\title{
Epidemiology of imaging-detected bone stress injuries in athletes participating in the Rio de Janeiro 2016 Summer Olympics
}

\author{
Daichi Hayashi, ${ }^{1,2}$ Mohamed Jarraya, 1,3 Lars Engebretsen, ${ }^{4,5,6}$ Michel D Crema, ${ }^{1,7,8}$ \\ Frank W Roemer, ${ }^{1,9}$ Abdalla Skaf, ${ }^{10}$ Ali Guermazi ${ }^{1}$
}

'Department of Radiology,

Quantitative Imaging

Center, Boston University

School of Medicine, Boston,

Massachusetts, USA

${ }^{2}$ Department of Radiology,

Stony Brook University School

of Medicine, Stony Brook, New

York, USA

${ }^{3}$ Department of Radiology,

Mercy Catholic Medical Center,

Darby, Pennsylvania, USA

${ }^{4}$ Medical and Scientific

Department, International

Olympic Committee, Lausanne,

Switzerland

${ }^{5}$ Department of Sports Medicine,

Oslo Sports Trauma Research

Center, Norwegian School of

Sport Sciences, Oslo, Norway

${ }^{6}$ Department of Orthopaedic

Surgery, Oslo University

Hospital, University of Oslo,

Oslo, Norway

${ }^{7}$ Department of Sports Medicine

National Institute of Sports

(INSEP), Paris, France

${ }^{8}$ Department of Radiology,

Saint-Antoine Hospital,

University Paris VI, Paris, France

${ }^{9}$ Department of Radiology،

University of Erlangen-

Nuremberg, Erlangen, Germany

${ }^{10}$ Department of Radiology,

HCor Hospital and ALTA

Diagnostic Center (DASA

group), São Paulo, Brazil

Correspondence to

Dr Daichi Hayashi, Department

of Radiology, Quantitative

Imaging Center, Boston

University School of Medicine,

Boston, MA 02118, USA;

Daichi.Hayashi@

stonybrookmedicine.edu

Received 18 June 2017 Revised 24 September 2017

Accepted 4 October 2017

Published Online First

26 October 2017

Check for updates

To cite: Hayashi $D_{\text {, }}$

Jarraya M, Engebretsen L,

et al. Br J Sports Med

2018:52:470-474.

\section{ABSTRACT}

Background Bone stress injuries are common in high-

level athletics.

Aim To describe the demographics, frequency and anatomical location of stress injuries (ie, stress reaction and stress fractures) in athletes at the Rio de Janeiro 2016 Summer Olympic Games.

Methods We recorded all sports injuries at the Rio de Janeiro 2016 Summer Olympics reported by the National Olympic Committee (NOC) medical teams and in the polyclinic and medical venues. Imaging was performed through the official IOC clinic within the Olympic Village, using digital X-ray cameras and $3 \mathrm{~T}$ and 1.5T magnetic resonance (MR) scanners. Images were read centrally and retrospectively by musculoskeletal radiologists with expertise in sports injuries.

Results 11274 athletes (5089 women (45\%), 6185 men (55\%)) from 207 NOCs participated in the study. 1101 injuries were reported. Imaging revealed 9 stress fractures (36\%) and 16 stress reactions (64\%) in 18 female and 7 male athletes (median age 25 years, age range 18-32). Stress injuries were mostly in the lower extremities (84\%), particularly tibia (44\%) and metatarsals (12\%), with two in the lumbar spine (8\%). Stress injuries were most common in track and field athletes (44\%) followed by volleyball players (16\%), gymnastics (artistic) (12\%) and other type of sports. Conclusions Twenty-five bone stress injuries were reported, more commonly in women, mostly in the lower extremities and most commonly in track and field athletes. Our study demonstrates the importance of early imaging with MRI to detect stress reactions before they can progress to stress fractures.

\section{INTRODUCTION}

Bone stress injuries are common sports injuries which can disrupt training and competition. They are a major concern for sports medicine physicians. Injury surveillance during the Olympic Games serves an important role in injury prevention in high-level athletes. Despite the availability of publications related to epidemiology and imaging of sports injuries in general (including brief mentions of stress injuries) during recent Olympic Games, ${ }^{1-6}$ epidemiological data specifically dedicated to bone stress injury in the Olympic Games have not been well established in the literature. Searching PubMed with the phrases 'stress fracture', 'stress injury', 'stress reaction' and 'Olympic' reveals no prior publications dedicated to epidemiological data of stress fractures/ reaction at the Olympic Games. The oldest relevant paper, published in 1998, described stress fractures in 'the world class athlete'. ${ }^{7}$ Conversely, the most recent, published in 2016, was a review article describing tibial stress fractures in athletes. ${ }^{8}$ Previously published epidemiological descriptive studies from the Summer and Winter Olympics in 2008, 2010 and 2014 did not include dedicated analysis of bone stress injuries. ${ }^{3-5}$ Bone stress injuries may keep the athletes out of play for a longer period of time than traumatic fractures-an epidemiological study of 2439 elite football players over 10 years showed median length of time being absent from play was 65 days for stress fractures and 30 days for traumatic fractures. ${ }^{9}$ Moreover, MRI can be used as a tool to detect bone stress injuries. ${ }^{10-12}$ The aim of our study is to describe the demographics, frequency and anatomical location of stress injuries (ie, stress reaction and stress fractures) in athletes who participated in the Rio de Janeiro 2016 Summer Olympic Games. Paralympic Games were not included our study.

\section{METHODS}

This is a retrospective study of imaging data collected at the Rio 2016 Summer Olympic Games from the Radiological Information System (RIS) and Picture Archiving and Communication System (PACS). Medical and imaging services were open for 32 days from the opening of the Olympic Village on 24 July 2016, through the period of the Olympic Games (5-21 August) to the closing of the Olympic Village on 24 August 2016. All National Olympic Committee (NOC) medical teams reported the daily occurrence (or non-occurrence) of injuries on a standardised medical report form. We also retrieved the same information on all athletes treated for injuries in the polyclinic and all other medical venues by the Organising Committee of the Rio de Janeiro 2016 medical staff. We used the athlete accreditation number to control for injuries being treated by both groups. With duplicates, we retained the NOC data. Our study and intent to publish the data were approved by the IOC.

\section{Confidentiality}

We used the athlete accreditation number to query the IOC athlete database for age, gender and nationality of the injured athlete. We treated all information with strict confidence and de-identified our medical database after the Games. 
Informed consent was waived as all data in our epidemiological study were anonymised and unidentifiable. We obtained approval from the IOC to use anonymised imaging and demographic data for publication. Data were collected, stored and analysed in strict compliance with data protection and athletes' confidentiality.

\section{Data collection}

Diagnostic imaging was performed through the official IOC clinic within the Olympic Village, using digital X-ray cameras: Discovery XR656 Advanced Digital Radiography System (GE Healthcare, Brazil) and 3T Discovery MR750w and $1.5 \mathrm{~T}$ Optima $450 \mathrm{MRw}$ MR scanners (both GE Healthcare, Brazil). Imaging data were retrospectively collected from the Radiological Information System. Anonymised demographic information was also collected for all athletes diagnosed with bone stress injuries on imaging. These data were stratified according to gender, age, participating country, type of sport and anatomical body part. MRI were obtained using fluid-sensitive fast spin echo sequences such as (T2-weighted and proton density-weighted) with fat suppression in axial, sagittal and coronal planes and T1-weighted in two planes as appropriate for each anatomical location. During the Rio 2016 Summer Olympic Games, 607 MRIs were performed for athletes presenting to IOC clinic Imaging Centre. All of these MRIs were centrally read for the purpose of our study regardless of presenting symptoms.

\section{Imaging interpretation}

All radiographs were reviewed for the presence of a bone stress injury. Stress fracture diagnosed radiographically by the presence of sclerosis, periosteal reaction/elevation, cortical thickening and/or a fracture line at the site of bone pain in an athlete without frank trauma. Bone stress reaction was defined as an ill-defined area of hyperintensity on fluid-sensitive fast spin echo MRI representing marrow oedema at a symptomatic site with no definite demonstrable fracture on radiography or MRI. We used the Fredericson classification system for medial tibial stress syndrome ${ }^{13}$ (figure 1) (grade $0=$ normal; grade 1 =periosteal oedema; grade $2=$ marrow oedema visible on T2-weighted images only; grade $3=$ marrow oedema visible on both T1-weighted and T2-weighted images; grade $4 \mathrm{a}=$ intracortical signal changes in multiple focal areas; grade $4 b=$ linear region of intracortical signal changes). All cases in our study had gradual onset of pain either prior to or during the Olympic Games without a specific traumatic episode as a trigger. Bone marrow oedema on MRI in athletes with a specific recorded episode of trauma that lead to imaging studies were not considered as stress injuries and therefore were excluded from our study. Two board-certified

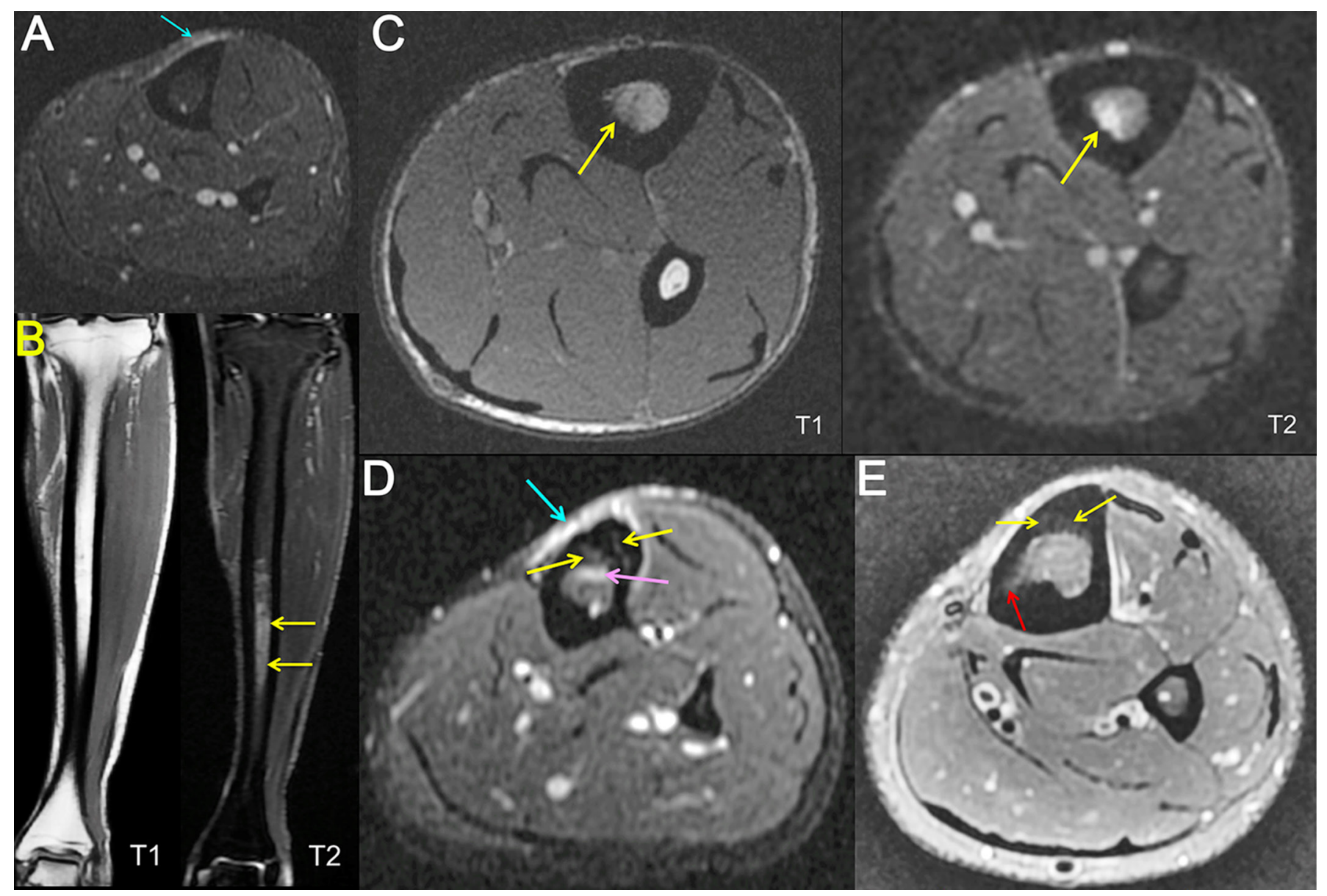

Figure 1 Examples of each grade of medial tibial stress syndrome according to the Fredericson classification. (A) Grade 1—isolated periosteal oedema (light blue arrow). (B) Grade 2-marrow oedema (yellow arrows) visible on T2-weighted image only and normal marrow signal on T1weighted image. (C) Grade 3-marrow oedema visible on both T1-weighted and T2-weighted images (yellow arrows), without cortical disruption or periosteal reaction. (D) Grade 4a-intracortical signal changes in multiple focal areas (yellow arrows), periosteal oedema (light blue arrow) and marrow oedema (pink arrow). (E) Grade 4b-linear hyperintensity (red arrow) and intra-cortical signal changes (yellow arrows). 


\begin{tabular}{ll}
\hline Table 1 Grades of tibial stress injuries & \\
\hline Grades of medial tibial stress injuries & Number of cases $(\%)$ \\
\hline 1 & $1(11)$ \\
2 & $2(22)$ \\
3 & $5(56)$ \\
4 & $1(11)$ \\
Total & $9(100)$ \\
\hline
\end{tabular}

musculoskeletal radiologists centrally and independently reviewed radiographs and MRI, in a retrospective fashion beyond the onsite clinical reporting, for the presence and type of stress injuries, which were classified into stress reaction and stress fracture based on imaging findings. For cases in which there were discrepancies in reading between the two readers, a third board-certified musculoskeletal radiologist acted as an adjudicator and mutual consensus was reached following discussion.

\section{RESULTS}

In total, 11274 athletes (5089 women (45\%), 6185 men (55\%)) from 207 NOCs participated in the study. NOC and Rio 2016 medical staff reported 1101 injuries. Centralised review of radiological images revealed 9 stress fractures and 16 stress reactions (total 25 stress injuries, accounting for approximately $2 \%$ of all injuries), in 18 female and 7 male athletes (median age 25 years, age range 18-32). Both types of stress injuries were more common in female athletes. Age range and median age were similar for both stress fractures and stress reaction (overall age range 18-30 years for stress fractures, 19-32 years for stress reactions, median 25 years for both). Stress injuries were seen in athletes representing countries in North and South America (stress fracture-Puerto Rico one; stress reaction-Brazil two, Canada one), Europe (stress fracture-one from Azerbaijan, Georgia, Portugal, Romania and Ukraine; stress reaction-two from Netherlands and Ukraine, one from Romania), Africa (stress fracture-two from Egypt, one from Cameroon and Ethiopia; stress reaction-two from Cameroon, one from Algeria, South Africa and Tunisia) and the Middle East (stress reaction-one from Bahrain and Saudi Arabia), but interestingly not from any countries in Fareast Asia or Oceania.

Two athletes were diagnosed with stress fractures by radiography alone without MRI. Three of the stress fractures diagnosed by MRI were radiographically occult. Nine patients had MRI-detected stress reaction/fracture of the tibia (figure 1). Table 1 summarises the distribution of tibial stress injuries according to the Fredericson classification system for medial tibial stress syndrome. ${ }^{13}$ Twenty-one out of 25 stress injuries were seen in the lower extremities (84\%), most commonly in tibia $(44 \%, \mathrm{n}=11)$, followed by metatarsal $(12 \%, \mathrm{n}=3$, figure 2$)$, fibula $(8 \%, n=2)$, femoral neck $(8 \%, n=2)$, navicular bone $(4 \%, n=1$, figure 3 ) and sesamoid bone of the foot $(4 \%, n=1)$. Two cases were found in the lumbar spine $(8 \%$, figure 4$)$, one in the metacarpals (4\%) and one in the iliac bone (4\%) (table 2).

Stress injuries were most commonly seen in track and field athletes $(44 \%, \mathrm{n}=11)$ followed by volleyball players $(16 \%$, $\mathrm{n}=4)$, gymnastics (artistic) $(12 \%, \mathrm{n}=3)$, fencing $(8 \%, \mathrm{n}=2)$ and weightlifting $(8 \%, n=2)$. One case $(4 \%)$ each was seen in gymnastics (rhythmic), triathlon and handball (table 3 and 4).

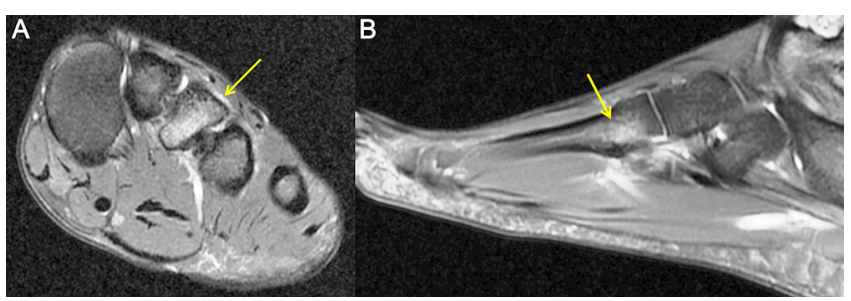

Figure 2 Stress reaction of the base of the third metatarsal in a female sprinter, diagnosed on axial (A) and sagittal (B) fat-suppressed proton density-weighted MRI (arrow). Note the periosteal oedema as well as the bone marrow oedema within the base of the third metatarsal without a discrete fracture line.

\section{DISCUSSION}

Our study included 25 bone stress injuries reported during the Rio de Janeiro 2016 Summer Olympic Games. They occurred more commonly in women, mostly in the lower extremities and most commonly in track and field athletes. According to published data describing injuries during the London 2012 Olympics, ${ }^{2} 6$ stress fractures were reported (6 of 174 injuries leading to the absence from training or competition by $>1$ week, approximately $3 \%)^{2}$ Based on unpublished data, there were 40 stress injuries (22 stress reactions, 18 stress fractures; approximately $3 \%$ of total 1361 injuries) during the London 2012 Olympics, which is similar to the proportion of total injuries in our study.

More female athletes suffered from bone stress injuries than male athletes (18 vs 7 ) despite there being fewer female athletes than male in the Rio de Janeiro Olympics (5089 women (45\%), 6185 men (55\%)). Studies have shown risk of bone stress injuries in female athletes can be predicted using an available risk-stratification tool. ${ }^{14}{ }^{15}$ In track and field athletes, higher MRI grade of bone stress injuries, lower bone mineral density and skeletal sites of predominant trabecular bone structures were shown to be associated with delayed recovery of bone stress injuries. ${ }^{16}$ Sports medicine physicians may be aided by the knowledge of these risk factors, as well as nutritional and menstrual factors, in determining the severity of the injury and time to return to sport in female athletes.

In terms of global geographical distribution of stress injuries, athletes from North and South America, Africa, Europe and the Middle East were included but interestingly no athletes from Fareast Asia or Oceania (including Australia and New Zealand) had bone stress injuries. The reason is unknown and may be coincidental, but an in-depth epidemiological study

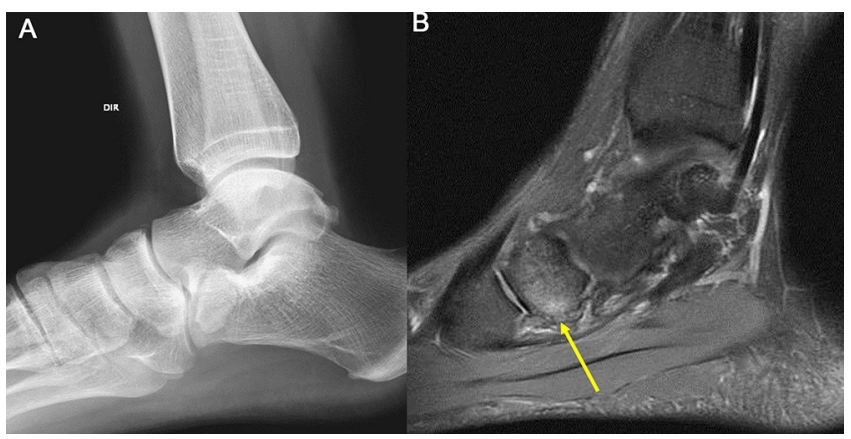

Figure 3 Tarsal navicular stress reaction in the left foot in a female fencing athlete. This lesion was radiographically occult $(A)$ and detected only on MRI (B, sagittal fat-suppressed proton density-weighted sequence, arrow). 


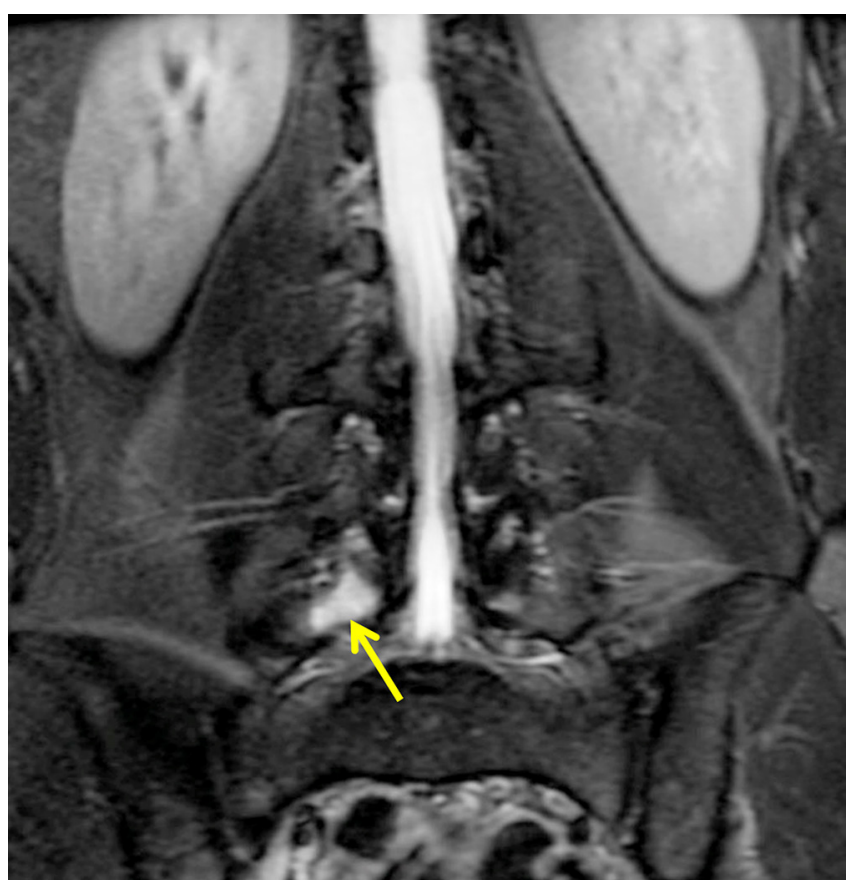

Figure 4 Stress reaction of the right $L 5$ pars interarticularis spreading to the right transverse process (arrow) in a female weightlifter detected on coronal fat-suppressed T2-weighted MRI.

to assess for possible multifactorial risks might be worth considering.

Bone stress injuries in the lower extremities, particularly tibia, foot and ankle, are common. ${ }^{3}$ Factors such as bone vascularity, training regimen and equipment can increase the risk of stress fracture. ${ }^{3}$ High-risk fractures in such locations as the anterior tibial diaphysis, navicular, proximal fifth metatarsal and medial malleolus can be challenging to manage and may require surgical intervention, especially in elite athletes who need to return to play quickly. ${ }^{3}$

Track and field athletes had the highest frequency of stress injuries followed by gymnastics and volleyball in our study, and interestingly this pattern was the same in the London 2012 Olympics. Given the consistent relatively high occurrence of stress injuries in these types of sports, participants are obvious targets for a prevention programme of stress injuries.

\begin{tabular}{|c|c|c|c|}
\hline Location & Stress fracture & Stress reaction & Total \\
\hline Lower extremity total & 8 & 13 & 21 \\
\hline Tibia & 5 & 6 & 11 \\
\hline Metatarsal & 1 & 2 & 3 \\
\hline Fibula & 0 & 2 & 2 \\
\hline Femoral neck & 1 & 1 & 2 \\
\hline Navicular & 1 & 1 & 2 \\
\hline Sesamoid of foot & 0 & 1 & 1 \\
\hline \multicolumn{4}{|l|}{ Spine } \\
\hline Lumbar spine & 0 & 2 & 2 \\
\hline \multicolumn{4}{|l|}{ Upper extremity } \\
\hline Metacarpals & 0 & 1 & 1 \\
\hline \multicolumn{4}{|l|}{ Pelvis } \\
\hline Iliac bone & 1 & 0 & 1 \\
\hline All & 9 & 16 & 25 \\
\hline
\end{tabular}

Table 3 Stress injuries by sport

\begin{tabular}{llcc}
\hline Sports & Stress fracture & Stress reaction & Total \\
\hline Athletics (track and field) & 4 & 7 & 11 \\
Volleyball & 2 & 2 & 4 \\
Gymnastics (artistic) & 0 & 3 & 3 \\
Fencing & 0 & 2 & 2 \\
Weightlifting & 1 & 1 & 2 \\
Gymnastics (rhythmic) & 1 & 0 & 1 \\
Handball & 1 & 0 & 1 \\
Triathlon & 0 & 1 & 1 \\
All & 9 & 16 & 25 \\
\hline
\end{tabular}

High intensity practice/training is inevitable at the Olympic level, and therefore early detection of a stress reaction before it progresses to fracture is important and is potentially an achievable goal. To accomplish this, early imaging with MRI in symptomatic patients with normal radiographs may be helpful; stress reaction cannot be detected on radiography and some stress fractures are radiographically occult, as demonstrated in our study. Currently, the prognostic value of screening and the effect of a prevention intervention are not well established in the literature. We suggest this is an interesting area to perform prevention studies with imaging including MRI and radiography. Moreover, asymptomatic grade I bone stress reactions seen on MRI are clinically non-significant and training can continue without developing fracture. ${ }^{17}$ MRI thus allows detection and assessment of the severity of bone stress injury, as well as helping to make management decisions and enabling follow-up of healing and/or progression, including prediction of recovery time based on the grades of bone stress injury. ${ }^{17} 18$ Our study also highlights the limited utility of radiography in the context of sports injuries at an elite level. According to American College of Radiology (ACR) Appropriateness Criteria published in May 2017, radiography remains the modality of choice for baseline imaging, although they do acknowledge the importance and necessity of MRI to diagnose radiographically occult stress fractures. ${ }^{19}$

It should be noted that some of our imaging findings may have already been present prior to the Olympic Games due to overuse and are not necessarily a result of the competition itself. Our study is limited by the fact that we only took into account bone stress injuries diagnosed on the basis of imaging. There could have been athletes who had such injuries but did not undergo imaging, or athletes who did not report their injuries to the polyclinic within the Olympic Village and thus could not be included in our study. Our study is a retrospective data analysis based on central rereading of the images, and thus our interpretation/diagnoses may differ from those established onsite by treating physicians at the Olympic Village Polyclinic. Thus, potential underestimation of stress injuries cannot be entirely excluded.

\section{CONCLUSION}

Our study included 25 bone stress injuries reported during the Rio de Janeiro 2016 Summer Olympic Games. Stress reactions can only be diagnosed by MRI and some of the stress fractures were radiographically occult. Our study demonstrates the importance of early imaging with MRI to detect stress reactions before they progress to fractures. Sports physicians should be aware of risk factors for bone stress injuries in highlevel athletes, particularly female athletes. Such knowledge 
Table 4 Anatomical location of stress injuries by sport

\begin{tabular}{|c|c|c|c|c|}
\hline & Lower extremities & Upper extremities & Pelvis & Lumbar spine \\
\hline $\begin{array}{l}\text { Athletics } \\
(n=11 ; 44.0 \%)\end{array}$ & $\begin{array}{l}10(40.0 \%) \\
\text { Navicular (1) } \\
\text { Foot sesamoid (1) } \\
\text { Metatarsal (2) } \\
\text { Tibia (5) } \\
\text { Femoral neck (1) }\end{array}$ & 0 & 0 & $\begin{array}{l}1(4.0 \%) \\
\text { L4 pedicle (1) }\end{array}$ \\
\hline $\begin{array}{l}\text { Fencing } \\
(n=2 ; 8.0 \%)\end{array}$ & $\begin{array}{l}2(8.0 \%) \\
\text { Navicular (1) } \\
\text { Fibula (1) }\end{array}$ & 0 & 0 & 0 \\
\hline $\begin{array}{l}\text { Gymnastics (artistic) } \\
(n=3 ; 12.0 \%)\end{array}$ & $\begin{array}{l}2(8.0 \%) \\
\text { Tibia (1) } \\
\text { Fibula (1) }\end{array}$ & $\begin{array}{l}1(4.0 \%) \\
\text { Metacarpal (1) }\end{array}$ & 0 & 0 \\
\hline $\begin{array}{l}\text { Gymnastics (rhythmic) } \\
(n=1 ; 4.0 \%)\end{array}$ & $\begin{array}{l}1(4.0 \%) \\
\text { Metatarsal (1) }\end{array}$ & 0 & 0 & 0 \\
\hline $\begin{array}{l}\text { Handball } \\
(n=1 ; 4.0 \%)\end{array}$ & $\begin{array}{l}1(4.0 \%) \\
\text { Tibia (1) }\end{array}$ & 0 & 0 & 0 \\
\hline $\begin{array}{l}\text { Triathlon } \\
(n=1 ; 4.0 \%)\end{array}$ & $\begin{array}{l}1(4.0 \%) \\
\text { Femoral neck (1) }\end{array}$ & 0 & 0 & 0 \\
\hline $\begin{array}{l}\text { Volleyball } \\
(n=4 ; 16.0 \%)\end{array}$ & $\begin{array}{l}4(16.0 \%) \\
\text { Tibia (4) }\end{array}$ & 0 & 0 & 0 \\
\hline $\begin{array}{l}\text { Weightlifting } \\
(n=2 ; 8.0 \%)\end{array}$ & 0 & 0 & $\begin{array}{l}1(4.0 \%) \\
\text { Iliac bone (1) }\end{array}$ & $\begin{array}{l}1(4.0 \%) \\
\text { L5 pars interarticularis }(1)\end{array}$ \\
\hline Total $(n=25)$ & $21(84.0 \%)$ & $1(4.0 \%)$ & $1(4.0 \%)$ & $2(8.0 \%)$ \\
\hline
\end{tabular}

may be clinically useful for early detection of bone stress injuries and prevention of unwanted consequences of such injuries resulting in prolonged recovery time and return to sports.

\section{What are the new findings?}

Twenty-five bone stress injuries were reported during the Rio de Janeiro 2016 Summer Olympic Games.

- They occurred more commonly in women, mostly in the lower extremities and most commonly in track and field athletes.

- Our study demonstrates the importance of early imaging with MRI to detect stress reactions before they progress to fractures.

Correction notice This article has been corrected since it was published Online First. One affiliation has been corrected.

Acknowledgements The authors would like to thank $10 \mathrm{C}$ members and all staff of Olympic Village imaging centre and sports physicians/radiologists who provided clinical service.

Competing interests Ali Guermazi is the President of Boston Imaging Core Lab (BICL), LLC, and a Consultant to Merck Serono, AstraZeneca, Pfizer, GE Healthcare, OrthoTrophix, Sanofi and TissueGene. Frank Roemer and Michel Cremaare shareholders of BICL, LLC. Lars Engebretsen is a consultant to Arthrex and Smith and Nephew. The remaining authors have no conflicts of interest to disclose.

Ethics approval The research was approved by $I O C$ as well as ethics committee of South-Eastern Norway Regional Health Authority (\#S-07196C).

Provenance and peer review Commissioned; externally peer reviewed.

Data sharing statement Unpublished data are not available for sharing.

(c) Article author(s) (or their employer(s) unless otherwise stated in the text of the article) 2018. All rights reserved. No commercial use is permitted unless otherwise expressly granted.

\section{REFERENCES}

1 Guermazi A, Hayashi D, Jarraya M, et al. Imaging depicted sports injuries at Rio de Janeiro 2016 Summer Olympic Games: Retrospective analysis of utilization of diagnostic imaging services. Radiology 2017.

2 Engebretsen L, Soligard T, Steffen K, et al. Sports injuries and illnesses during the London Summer Olympic Games 2012. Br J Sports Med 2013;47:407-14.
3 Junge A, Engebretsen L, Mountjoy ML, et al. Sports injuries during the Summer Olympic Games 2008. Am J Sports Med 2009;37:2165-72.

4 Engebretsen L, Steffen K, Alonso JM, et al. Sports injuries and illnesses during the Winter Olympic Games 2010. Br J Sports Med 2010;44:772-80.

5 Soligard T, Steffen K, Palmer-Green D, et al. Sports injuries and illnesses in the Sochi 2014 Olympic Winter Games. Br J Sports Med 2015;49:441-7.

6 Bethapudi S, Budgett R, Engebretsen L, et al. Imaging at London 2012 summer Olympic Games: analysis of demand and distribution of workload. Br J Sports Med 2013:47:850-6.

7 Jensen JE. Stress fracture in the world class athlete: a case study. Med Sci Sports Exerc 1998:30:783-7.

8 Feldman JJ, Bowman EN, Phillips BB, et al. Tibial stress fractures in athletes. Orthop Clin North Am 2016;47:733-41.

9 Larsson D, Ekstrand J, Karlsson MK. Fracture epidemiology in male elite football players from 2001 to 2013: 'How long will this fracture keep me out?'. Br J Sports Med 2016;50:759-63.

10 Bergman AG, Fredericson M, Ho C, et al. Asymptomatic tibial stress reactions: MRI detection and clinical follow-up in distance runners. AJR Am J Roentgenol 2004; 183:635-8

11 Dobrindt O, Hoffmeyer B, Ruf J, et al. Estimation of return-to-sports-time for athletes with stress fracture - an approach combining risk level of fracture site with severity based on imaging. BMC Musculoskelet Disord 2012;13:139.

12 Slocum KA, Gorman JD, Puckett ML, et al. Resolution of abnormal MR signal intensity in patients with stress fractures of the femoral neck. AJR Am J Roentgenol 1997:168:1295-9.

13 Fredericson M, Bergman AG, Hoffman KL, et al. Tibial stress reaction in runners. Correlation of clinical symptoms and scintigraphy with a new magnetic resonance imaging grading system. Am J Sports Med 1995;23:472-81.

14 Tenforde AS, Carlson JL, Chang A, et al. Association of the female athlete triad risk assessment stratification to the development of bone stress injuries in collegiate athletes. Am J Sports Med 2017;45:302-10.

15 Barrack MT, Gibbs JC, De Souza MJ, et al. Higher incidence of bone stress injuries with increasing female athlete triad-related risk factors: a prospective multisite study of exercising girls and women. Am J Sports Med 2014;42:949-58.

16 Nattiv A, Kennedy G, Barrack MT, et al. Correlation of MRI grading of bone stress injuries with clinical risk factors and return to play: a 5 -year prospective study in collegiate track and field athletes. Am J Sports Med 2013;41:1930-41.

17 Kiuru MJ, Niva M, Reponen A, et al. Bone stress injuries in asymptomatic elite recruits: a clinical and magnetic resonance imaging study. Am J Sports Med 2005:33:272-6.

18 Nye NS, Covey CJ, Sheldon L, et al. Improving diagnostic accuracy and efficiency of suspected bone stress injuries. Sports Health 2016;8:278-83.

19 Bencardino JT, Stone TJ, Roberts CC, et al. ACR Appropriateness Criteria(®) Stress (Fatigue/Insufficiency) Fracture, Including Sacrum, Excluding Other Vertebrae. J Am Coll Radiol 2017:14:S293-S306. 